\title{
Magnitude of Nurses' Intention to Leave Their Jobs and Its Associated Factors of Nurses Working in Tigray Regional State, North Ethiopia: Cross sectional study
}

Reza Negarandeh ( $\square$ rnegarandeh@tums.ac.ir )

Woldegebriel Gebregziabher Kahsay

Adigrat University College of Health Sciences

Shahzad Pashaeypoor

Tehran University of Medical Sciences

Elham Navab

Tehran University of Medical Sciences

Research article

Keywords: Intention, Job, Hospital, Nurse, Tigray Region, Ethiopia

Posted Date: April 17th, 2020

DOI: https://doi.org/10.21203/rs.3.rs-22578/v1

License: (c) (i) This work is licensed under a Creative Commons Attribution 4.0 International License.

Read Full License 


\section{Abstract}

Introduction A significant number of nurses is leaving the health care sector. High rates of turnovers contribute to labor shortages of nursing and adversely affect patient outputs and nursing costs.

Objectives To determine the magnitude of nurses' intention to leave a job and its associated factors.

Methods A cross-sectional, analytical descriptive study design among 634 nurses working in Tigray Regional State general hospitals from March 2018 to 30 June 2019 was conducted. Clustered random sample nurses completed self-administered three-item Michigan Organizational Assessment Questionnaire during data collection. Descriptive and multiple logistic regression analyses were done using SPSS version $20,95 \%$ confidence interval and $p$-value $<0.05$ was considered.

Findings Response rate was $95.9 \%$. Nurses were with a mean of $33.60 \pm 9.71,10.07 \pm 9.54$, and $2.10 \pm$ 1.455 in years for age, work experience, and service in hospital respectively. About $56.4 \%$ were females, 95.4\% Orthodox, and $56.7 \%$ were Bachelors of Science in Nursing. The magnitude of nurses' intention to leave their jobs was $43.9 \%$. The male nurses were 1.5 times more likely $(A O R=1.565,95 \% \mathrm{Cl}=1.095-$ 2.237) had the intention to leave. Those nurses working in medical ward were also 2 times more likely $(A O R=1.886,95 \% \mathrm{Cl}=1.113-3.193)$ than working in the Out-Patient Department of the hospitals had the intention to leave.

Conclusions Nurses in hospitals intend to leave their jobs. Gender and working in medical ward are the predictors for their intentions. Health care policymakers are recommended to develop nurses' retention strategies and establish continuing education to socialize male nurses and set economic incentive strategies to encourage male nurses to stay in hospitals fulfilling their families' income to earn. Managers are recommended to make regular rotation of nurses within hospitals to minimize a possible burden in medical wards. For the quality nursing care, nursing managers should create a favorable environment in medical wards. Educators are recommended to increase the intake of the nursing students. This study did not show the cause and effect of variables. Therefore, other researchers are recommended to conducting longitudinal studies.

\section{Introduction}

All countries are urged to heed the signals of shortages because $40 \%$ of nurses will leave health employment in the next decade [1]. Globally, a nursing shortage is highly expected and will continue to be a major problem affecting health care delivery of the next [2]. Global nursing leaders had warned that stopping nurses from leaving their jobs prematurely is a critical issue for governments around the world as staff shortages escalate [3]. It's estimated that over 260,000 nurses leave the profession annually and are not being replaced as quickly as they leave. Even if replaced, new academic nurses do not have the same experience level as experienced nurses [4]. The shortage of nurses jeopardizes the quality of patient care and safety [5]. Similarly, the high rates of turnovers contribute to labor shortages of nursing and 
adversely affect patient outputs and nursing costs. This rate highlights the urgency of identifying and implementing strategies that effectively reduce the intention of nurses to leave their jobs [6].

Intent to leave had been studied from a variety of perspectives: intention to leave the profession, intention to leave a current position, turnover, and intent to stay in the profession[7]. For this study, intention to leave refers to the perceptions of employees toward their jobs to leave rather than their actual behaviors and is a significant indicator of personnel turnover [8], and also refers to an employee's expressed intention of leaving their current job in the near future[7].

There is scarce evidence for the status nurses' intention to leave in African countries including Ethiopia. Those all conducted in the country were not specifically among nurses working in hospitals. Most participants were health professionals and nurses in different level of health facilities. This study aimed to determine the magnitude of nurses' intention to leave their jobs and the factors associated with intention.

Therefore, the results of this study will be a source of evidence to improve the nurses' stay in their jobs and will inform policymakers, health managers, hospital managers, nursing administrators on the status of the nurses' intention to leave and it will be a baseline to other researchers. This study determined the magnitude and factors associated with nurses' intention to leave their jobs.

\section{Methods And Materials}

\section{Study setting}

Tigray Regional State is one of the nine national regional states of Ethiopia with a total of 6 million people. There are 5564 nurses are working in the regional state [9]. The region has six administrative zones. One zone consists of two or more general hospitals and totally 15 general hospitals are in the region. A general hospital serves 1-1.5 million people in year, equipped with 50 beds and 100 to 200 nurse employees. Zone is a third level political-administrative structure of Ethiopia. A zone is with a population of 400000 to 1.5 million people.

\section{Study design}

A cross-sectional, analytical descriptive study design using clustered random sampling was conducted from March 2018 to 30 June 2019. Participants were nurses working in general hospitals of Tigray Regional State, North Ethiopia.

\section{Study participants}

Eligible participants were selected using clustered random sampling. The nurses in the 15 general hospitals of the region were clustered into the six zones due to the variation in their establishment and degree of service complexity. Out of the six zones, we selected four zones in a simple random sampling using lottery method. All nurses in randomly selected zones (Central, Western, Southern and Mekelle 
zones) which consists 10 general hospitals were the participants. The nurses working in the ten general hospitals within the randomly selected administrative zones were assessed for eligibility criteria. The eligibility criteria for the participant selection were as follows: Being a Bachelor of Science in Nursing, Clinical nurses, and other nurse specialists; Nurses with at least 12 months of work experience in general hospitals; Nurses who was voluntary to participate; Being able to read and complete the questionnaire; and nurses without any known mental health problems that would impede study participation.

\section{Sample size}

A single proportion formula was used to determine the sample size using the following assumptions (level of confidence is $95 \%$ at $z 1-\alpha / 2)$ : a $5 \%$ margin of error $(d=0.05)$. To get maximum samples, $50 \%$ proportion was used since there was no previous study on the intention to leave in Tigray Regional State and to get an adequate sample size. Based on these assumptions, the actual sample size of the study was computed as follows for the total population of 1581 nurses that were working in the general hospitals.

$$
\begin{aligned}
& \mathrm{n}=\frac{\left.\left(\mathrm{z}^{\alpha} /\right)^{2}\right)^{2} p(1-p)}{d^{2}} \quad \begin{aligned}
\text { Where } & \mathrm{n}=\text { sample size } \\
\mathrm{p} & =\text { expected proportion }(0.5) \\
\mathrm{d} & =\text { margin of error }(0.05)
\end{aligned}
\end{aligned}
$$

$\mathrm{n}=(1.96)^{2} 0.5(1-0.5)$

$(0.05)^{2}$

$\mathrm{n}=\underline{(3.842 \times 0.5 \times 0.5)}$

0.0025

$\mathrm{n}=384$

For the non-response rate, $10 \%$ of the sample was added and the design effect was also considered to reach the maximum nurse participants; the total sample size is $(384+38.4) \times 1.5=634$. A total of 634 sample sizes were used for this study.

\section{Data Collection}

A self-administered questionnaire was used for data collection. To ensure data quality, training for 2 days was given to data collectors and supervisors on general objective and techniques of administering the questionnaires. Detailed information about the objective of the study was also explained to all participants before the questionnaire administration. The questionnaires were administered to the nurse participants at the same time in each general hospital. To increase the response rate, efforts were done to get official cooperation by all levels of hospital managers to minimize interference with the data collection. The researcher checked for the completeness of questionnaires on a daily bases.

\section{Outcome measures}


The nurses' socio-demographic characteristics age, sex, marital status, education, religion, work experience, hospital experience, monthly income, and their work conditions workloads, work shifts, working units, number of nurses in a unit, and assigned working administrative zones were predictors of outcome. The outcome variable is intention to leave defined as an individual contemplating quitting his or her current job, or the person's stated intention to leave the organization within some specified period [10].

Intention to leave job was measured using the three items, seven-point Likert Scale Michigan Organizational Assessment Questionnaire (MOAQ). The MOAQ was developed by Fichman (1979) to measure nurses' intention to leave a job [11]. The values of the scale is in a range of one to seven. Item one (MOAQ1) of the measurement: "How likely is that you will actively look for a new job of the next year". For item one, seven - point Likert Scale responses were the lowest "not at all likely", "disagree", "somewhat likely", "neutral", "quite likely", "agree" and "extremely likely". Item two (MOAQ2): "I often think about quitting". Item three (MOAQ3): "I will probably look for a new job next year". For both MOAQ2 and MOAQ3 items, the scale is from "strongly disagreeing", "moderately disagree", "slightly disagree", "uncertain", "slightly agree", "moderately agree" and to "strongly agree".

The questionnaire was translated into the local language for better understanding of participants. A forward-translation into the local language was done by expert nurses. The translated questionnaire was back-translated by an English teacher into the original English version of its consistency. The questionnaire was pretested before the actual data collection of $6 \%$ of the sample size in Adigrat General Hospital. Item reliability analysis was done to see internal consistency. Based on the item reliability analysis test, the internal consistency of the items is Cronbach's alpha 0.875 in this study.

\section{Data analysis}

The questionnaires were checked for completeness, coded and entered into SPSS version 20 for data cleaning and analysis. Mean and standard deviation were determined for continuous variables. Categorical variables were summarized using frequency distributions and percentages. The data were presented in tables. Sum scores for the intention to leave ranged from one to 21 . Nurses who scored less than twelve were not considered as having the intention to leave, and those scored twelve or more were said to have an intention to leave [12]. Binary logistic regression analysis was run to identify factors associated with the intention to leave. All variables that showed statistically significant association with the intention to leave were included in the multiple logistic regression analysis to determine independent predictors of intention to leave. Crude Odds Ratio (COR) and Adjusted Odds Ratio (AOR) at a 95\% confidence interval $(\mathrm{Cl})$ with the $\mathrm{p}$-value less than 0.05 were used to control the potential confounding variables.

\section{Results}

Among the 634 nurses, 608 returned the filled questionnaires which indicated $95.9 \%$ response rate. The $343(56.4 \%)$ of them were females. The mean age in year was $33.60 \pm 9.71$. Majority, $245(56.7 \%)$ were Bachelors of Science in Nursing. Most nurses 580(95.4\%) were Orthodox in religion. Their mean total 
work experience in year was $10.07 \pm 9.54$, the mean $2.10 \pm 1.455$ in year was the nurses' service in hospitals and the nurses had mean monthly income of $4820.33 \pm 1547.77$ in Ethiopian currency (ETB) (Table 1). 
Table 1

Socio-demographic characteristics of nurses in general hospitals of Tigray $(\mathrm{N}=608)$

\begin{tabular}{|c|c|c|}
\hline Characteristics & n & $\%$ \\
\hline \multicolumn{3}{|l|}{ Sex } \\
\hline Male & 265 & 43.60 \\
\hline Female & 343 & 56.40 \\
\hline \multicolumn{3}{|l|}{ Age in years } \\
\hline$<30$ & 313 & 51.50 \\
\hline $30-39$ & 105 & 17.30 \\
\hline $40-49$ & 132 & 21.70 \\
\hline $50-59$ & 58 & 9.50 \\
\hline \multicolumn{3}{|l|}{ Marital status } \\
\hline Single & 284 & 46.70 \\
\hline Married & 285 & 46.90 \\
\hline Separated(divorced or widowed) & 39 & 6.40 \\
\hline \multicolumn{3}{|l|}{ Religion } \\
\hline Orthodox & 580 & 95.40 \\
\hline Other religions & 28 & 4.60 \\
\hline \multicolumn{3}{|l|}{ Educational level } \\
\hline Diploma in clinical nurse & 242 & 39.80 \\
\hline Bachelor of Science & 245 & 56.70 \\
\hline Master and others & 21 & 3.50 \\
\hline \multicolumn{3}{|l|}{ Work experience in years } \\
\hline $1-4$ & 257 & 42.30 \\
\hline $5-9$ & 106 & 17.40 \\
\hline $10-14$ & 88 & 14.50 \\
\hline $15-19$ & 33 & 5.40 \\
\hline$\geq 20$ years & 124 & 20.40 \\
\hline
\end{tabular}

*ETB = Ethiopian money in Birr); USD = United States Dollar, One USD was 28.5 ETB in Jan. 2019. 


\begin{tabular}{|lll|}
\hline Characteristics & n & \% \\
\hline Monthly income & & \\
\hline$\leq 4000$ ETB $(\leq 140$ USD*) & 207 & 34.00 \\
\hline $4001-6000$ ETB(140-210.5 USD) & 300 & 49.30 \\
\hline$\geq 6001 E T B(\geq 211$ USD) & 101 & 16.60 \\
\hline *ETB = Ethiopian money in Birr); USD = United States Dollar, One USD was 28.5 ETB in Jan. 2019. \\
\hline
\end{tabular}

About 222(36.5\%) of nurse were with workload of 48 hours or more of a week (mean $=47.47 \pm 12.50$ hours/week). The 268(44.1\%) were assigned at night to shift. Half of them (50.5\%) were working with 10 to 15 nurse colleagues in the units they work (Table 2). 
Table 2

Working conditions of nurses in general hospitals of Tigray Region $(\mathrm{N}=608)$

\begin{tabular}{|lcc|}
\hline Characteristics $\mathrm{n} \%$ & & \\
\hline Workload & 386 & 63.50 \\
\hline$<48$ hours/week & 222 & 36.50 \\
\hline$\geq 48$ hours/week & & \\
\hline Working shifts & 67 & 11.00 \\
\hline Day shift only & 268 & 44.10 \\
\hline Night shift only & 273 & 44.90 \\
\hline Rotation shift & & \\
\hline Ward work in & 137 & 22.50 \\
\hline Out Patient Department(OPD) & 108 & 17.80 \\
\hline Emergency Department & 115 & 18.90 \\
\hline Medical Ward & 111 & 18.30 \\
\hline Surgical Ward & 137 & 22.50 \\
\hline Maternal and child care (MCH) & 30 & 4.90 \\
\hline Number of nurses working with in a ward \\
\hline$<5$ Nurses & 127 & 20.90 \\
\hline $5-10$ Nurses & 319 & 50.50 \\
\hline $11-15$ nurses & 132 & 21.70 \\
\hline$\geq 16$ Nurses & & \\
\hline
\end{tabular}

The study found that $267(439 \%)$ of nurses had an intention to leave their jobs. Half (51.2\%) of nurses are actively looking for a new job in the next year. About 248 (40.8\%) of nurses think to quit their job. More than half, 342(56.3\%) of nurses have the probability to look another new job in the next year (Table 3). 
Table 3

Nurses' intention to leave their jobs in general hospitals of Tigray Region $(\mathrm{N}=608)$

\begin{tabular}{|c|c|c|c|}
\hline Values & $\begin{array}{l}\text { Actively looking for } \\
\text { new job n (\%) }\end{array}$ & $\begin{array}{l}\text { Think to } \\
\text { quit job } \\
\text { n (\%) }\end{array}$ & $\begin{array}{l}\text { The probability to look another } \\
\text { new job n (\%) }\end{array}$ \\
\hline & MOAQ*1 & MOAQ2 & MOAQ3 \\
\hline $\begin{array}{l}\text { Strongly disagree/Not } \\
\text { at all likely }\end{array}$ & $221(36.30)$ & $274(45.10)$ & 194(31.90) \\
\hline $\begin{array}{l}\text { Moderately } \\
\text { disagree/Disagree }\end{array}$ & $44(7.20)$ & $56(9.20)$ & $41(6.70)$ \\
\hline $\begin{array}{l}\text { Slightly } \\
\text { disagree/somewhat } \\
\text { likely }\end{array}$ & $32(5.30)$ & $30(4.90)$ & $31(5.10)$ \\
\hline Uncertain/Neutral & $84(13.80$ & $77(12.70)$ & $110(18.10)$ \\
\hline $\begin{array}{l}\text { Slightly agree/quite } \\
\text { likely }\end{array}$ & $51(8.40)$ & $63(10.40)$ & $50(8.20)$ \\
\hline Moderately agree/Agree & 71(11.70) & $29(4.80)$ & $39(6.40)$ \\
\hline $\begin{array}{l}\text { Strongly } \\
\text { agree/Extremely likely }\end{array}$ & 105(17.30) & $73(13.00)$ & $143(23.50)$ \\
\hline
\end{tabular}

The bivariate analysis showed that male nurses were 2 times more likely intended to leave than females $(\mathrm{OR}=1.706,95 \% \mathrm{Cl}=1.233-2.369)$. Nurses with age $40-49$ and $50-59$ years were less likely $(\mathrm{OR}=0.510$, $95 \% \mathrm{Cl}=0.333-0.779)$ and $(\mathrm{OR}=0.423,95 \% \mathrm{Cl}=0.230-0.776)$ intended to leave compared to age less than 30 years respectively. The married and separated nurses were also less likely $(\mathrm{OR}=0.667,95 \% \mathrm{Cl}=$ $0.478-0.929)$ and $(\mathrm{OR}=0.393,95 \% \mathrm{Cl}=0.188-0.819)$ intended to leave than single nurses respectively.

Nurses with work experience of 20 years or more were less likely ( $\mathrm{OR}=0.541,95 \% \mathrm{Cl}=0.347-0.844)$ had the intention to leave compared to work experience 1 to 4 years. Specifically to nurses with hospital work experience 15 to 19 years and 20 years or more were less likely $(\mathrm{OR}=0.346,95 \% \mathrm{Cl}=0.158-0.757)$ and $(\mathrm{OR}=0.558,95 \% \mathrm{Cl}=0.339-0.919)$ to leave compared to 1 to 4 years of hospital service respectively. Those nurses working in emergency unit, medical ward and maternal and child health $(\mathrm{MCH})$ were 2 times more likely $(\mathrm{OR}=1.778,95 \% \mathrm{Cl}=1.061-2.981),(\mathrm{OR}=1.948,95 \% \mathrm{Cl}=1.172-3.238)$ and $(\mathrm{OR}=$ $1.679,95 \% \mathrm{Cl}=1.032-2.732$ ) than those working in the Out-Patient Department had an intention to leave respectively. Nurses working in Western Zone and Southern Zone were 2 times more likely $(\mathrm{OR}=1.833$, $95 \% \mathrm{Cl}=1.067-3.149)$ and $(\mathrm{OR}=1.917,95 \% \mathrm{Cl} 1.227-2.993)$ intended to leave than working in Mekelle Zone respectively (Table 4). 
Table 4

Multiple logistic regression analysis for predictors of nurses' intention to leave

Characteristics

Intention to leave $(\mathrm{N}=608)$

Yes (\%)

No (\%)

COR

Cl

AOR

Sex

Male

Female

131(38.20)

212(61.80)

1.00

Reference group

\section{Age in years}

$<30$

155(49.50)

158(50.50)

1.00

Reference

group

$30-39$

$51(48.60) \quad 54(51.40)$

0.963

0.619-1.498

0.977

1.816

$40-49$

44(33.30)

$88(66.70)$

0.510

$0.333-0.779 *$

0.640

$0.294-$

1.393

$\geq 50$

17(29.30)

41(70.70)

0.423

$0.230-0.776 *$

0.526

$0.208-$

1.331

\section{Marital status}

Single

Married

Separated

Total experience in years

1-4

125(48.60)

132(51.40)

1.00

Reference group

5-9

54(50.90)

52(49.10)

1.097

$0.697-1.724$

1.240

$10-14$

$34(38.60)$

54(61.40)

0.667

0.406-1.090

0.970

2.346

15-19
Reference
group

$0.478-0.929$ *

0.840

0.741

$0.188-0.819 *$
$0.571-$

1.236
$0.310-$ 1.645

12(36.40) 21(63.60)

0.603

$0.285-1.278$

1.252

0.447-

2.106

$0.419-$

3.735 


\begin{tabular}{|c|c|c|c|c|c|c|}
\hline \multirow[t]{2}{*}{ Characteristics } & \multicolumn{6}{|c|}{ Intention to leave $(N=608)$} \\
\hline & Yes (\%) & No (\%) & COR & $\mathrm{Cl}$ & AOR & $\mathrm{Cl}$ \\
\hline$\geq 20$ & 42(33.90) & $82(66.10)$ & 0.541 & $\begin{array}{l}00.347- \\
0.844^{\star}\end{array}$ & 1.040 & $\begin{array}{l}0.421- \\
2.570\end{array}$ \\
\hline \multicolumn{7}{|c|}{ Hospital service in years } \\
\hline $1-4$ & 155(48.10) & 167(51.90) & 1.00 & $\begin{array}{l}\text { Reference } \\
\text { group }\end{array}$ & 1.00 & \\
\hline $5-9$ & $50(46.30)$ & $58(53.70)$ & 0.929 & $0.600-1.438$ & 1.105 & $\begin{array}{l}0.602- \\
2.028\end{array}$ \\
\hline $10-14$ & $24(42.90)$ & $32(57.10)$ & 0.808 & $0.456-1.433$ & 1.154 & $\begin{array}{l}0.537- \\
2.480\end{array}$ \\
\hline $15-19$ & $9(24.30)$ & $28(75.70)$ & 0.346 & $0.158-0.757^{\star}$ & 0.694 & $\begin{array}{l}0.257- \\
1.877\end{array}$ \\
\hline$\geq 20$ & $29(34.10)$ & $56(65.9)$ & 0.558 & $0.339-0.919 *$ & 1.052 & $\begin{array}{l}0.469- \\
2.360\end{array}$ \\
\hline \multicolumn{7}{|l|}{ Ward/Unit } \\
\hline $\begin{array}{l}\text { Out Patient } \\
\text { Department }\end{array}$ & $47(34.30)$ & $90(65.70)$ & 1.00 & $\begin{array}{l}\text { Reference } \\
\text { group }\end{array}$ & 1.00 & \\
\hline Emergency & $52(48.10)$ & $56(51.90)$ & 1.778 & $1.061-2.981^{\star}$ & 1.692 & $\begin{array}{l}0.987- \\
2.899\end{array}$ \\
\hline Medical & $58(50.40)$ & $57(49.60)$ & 1.948 & $1.172-3.238^{\star}$ & 1.886 & $\begin{array}{l}1.113- \\
3.193^{\star \star}\end{array}$ \\
\hline Surgical & $46(41.40)$ & $65(58.60)$ & 1.355 & $0.808-2.272$ & 1.140 & $\begin{array}{l}0.663- \\
1.960\end{array}$ \\
\hline Maternal \& child care & 64(46.70) & 73(53.30) & 1.679 & $1.032-2.732^{\star}$ & 1.505 & $\begin{array}{l}0.903- \\
2.508\end{array}$ \\
\hline \multicolumn{7}{|l|}{ Administrative Zone } \\
\hline Central Zone & $75(42.10)$ & 103(57.90) & 1.396 & $0.882-2.208$ & 1.243 & $\begin{array}{l}0.769- \\
2.007\end{array}$ \\
\hline Western Zone & $44(48.90)$ & $46(51.10)$ & 1.833 & $1.067-3.149 *$ & 1.308 & $\begin{array}{l}0.727- \\
2.354\end{array}$ \\
\hline Southern Zone & $100(50.00)$ & $100(50.00)$ & 1.917 & $1.227-2.993^{\star}$ & 1.595 & $\begin{array}{l}0.993- \\
2.559\end{array}$ \\
\hline Mekelle Zone & 48(43.30) & $92(65.70)$ & 1.00 & $\begin{array}{l}\text { Reference } \\
\text { group }\end{array}$ & 1.00 & \\
\hline
\end{tabular}


The multiple logistic regressions showed that male nurses and nurses working in medical wards showed a significant statistical association with the intention to leave. The male nurses were 1.5 times more likely $(A O R=1.565,95 \% \mathrm{Cl}=1.095-2.237)$ compared to females had the intention to leave. Those nurses working in medical ward were 2 times more likely ( $A O R=1.886,95 \% \mathrm{Cl}=1.113-3.193$ ) than those working in the Out-Patient Department of hospitals had the intention to leave (Table 4).

\section{Discussion}

Most studies in Ethiopia on intention to leave were done among health professional participants in general and among the nurses working in different study settings. This hospital-based cross-sectional study has attempted to determine the magnitude of nurses' intention to leave a job and identified the factors associated with the intention to leave.

The first study aim was to determine the magnitude of nurses' intention to leave their jobs and the result revealed that $43.9 \%$ of nurses intended to leave. Our finding shows consistency with study results of 46.1\% [13], 44.6\% [14], 42.5\% [15], and 40\% [16] in South Africa, Japan, Portugal, and Malaysian nurses' intention to leave their employment or job respectively. This similarity may be due to the similarity in socioeconomic factors and health policy of most countries with Ethiopia.

The magnitude of nurses' intention in this study is lower than previous $60.2 \%$ [17], and $59.4 \%$ among nurses [18] both in Western of Ethiopia, $50.2 \%$ at selected health facilities [19], and $50 \%$ in south part of Ethiopia [20]. This difference could be due to the variation in the level of the health facilities in the previous studies. The magnitude is also lower than the studies among Ethiopian health professionals $65 \%$ [21], 63.7\% [22], 61.3\% [23], 52.5\% [24] and 48.4\% [25] in Northwest, Southwest, and in the last three in western parts of Ethiopia respectively. This difference could be due to the difference in study participants of being mixed health professionals in the previous studies. The other reason could be due to difference in the levels of health facilities as study settings in those studies. Moreover, our result is lower than $60.90 \%$ in Jordan [26], $61 \%$ in South Korea [27] and $49.50 \%$ in Turkey [28]. The difference could be due to the difference in nurse participants' workplace setting, small sample size and the use of one item questionnaires in the other studies.

However, this finding is higher than the $10 \%$ [29], and $14 \%$ of nurses in the United States intended to leave [30], 16.2\% in Japan [31], 22.2\% in Australia [32], the two findings $21.9 \%$ [33] and 35.5\% [34] among Italian nurses intended to leave their current jobs. And higher than $33 \%$ of nurses in twelve European countries [35]. It is also higher than the 30.9\% in South Africa [36], 24.3\% [10] in Saudi Arabia and higher than three study results $22.50 \%$ [37], $17.20 \%$ [38] and $5.12 \%$ of nurses' intended to leave in China [39]. This high magnitude of intention may due to low payment for Ethiopian nurses [18, 19], nurses lacked remuneration and fringe benefits $[17,40,41]$, nurses work without compensation payments for weekends and holidays [42]. It could be also due to the reason nurses had poor interpersonal relationships with hospital managers, lacked respect from the managers, poor supervision and feedback systems. In addition to this, nurses are working in the unfair management system and leadership and with unfair 
treatment $[18,19,22]$ and nurses are getting little support $[17,20,41]$, less motivated in their work $[22,43]$ and less organizational commitment to the contributions they made [18]. Nurses are not involved in policy making, procedures, planning processes, and the nurses' opinions and suggestions are not part of solutions to the hospitals $[20,40]$.

The second aim of the study identified the factors associated with nurses' intention to leave their jobs. Being a male nurse is associated with the intention to leave. This association shows similarity with a study in Ethiopia, male health professionals were more likely than females to leave [23], and in a descriptive study, a higher number of male health professionals intended to leave their jobs [25]. The similarity could be due to the responsibility for males for their families' income and to get a higher salary in other positions.

The male gender as a predictor is consistent with two study results from Jordan which male nurses were more likely to leave their current position than female nurses [26, 44]. And also it is consistent with the study result from Italy that the male gender was listed as a predictor of intention to leave [34]. This similarity may be due to the similarity in socioeconomic factors of those countries with Ethiopia. However, South Korean female nurses had 2.52 times greater odds of intending to leave the workplace than did male nurses [27].

Moreover, working in the medical ward is a predictor of nurses' intention to leave their jobs. Other findings are in line with our findings, the majority of nurses moved from general departments of medical and surgical as an actual turnover in Israel [45]. In Singapore, nursing practice environments were identified as one with the strongest predictors of nurses' intention to leave [46]. In addition, the similarity is seen with a study among nurses working in closed-ward of psychiatric nursing in Israel reported a higher intent to leave [47]. Another from California showed that nurses working in adult non-intensive care units had an increased odds ratio of intention to leave [48]. This similarity may be due to the increment of patients with chronic diseases admission to the medical wards may cause burden on Ethiopian nurses. The burden may influence nurses to have high intention to leave their jobs.

\section{Limitations}

Since the study was cross-sectional, it may not be strong to demonstrate direct cause and effect between dependent and independent variables. There might be recalling biases. Participants social desirability bias might led to untruthful responses. Participants might face problem to grasp the meaning of some questions that seem clear. Even if all questions were clear all, participants might not understood the questions. All participants might not gave attention to read all the questions before answering. In addition to this, the characteristics of nurses in Tigray Regional State may not be generalized to all nurses in the country owing to differences in working conditions and the difference in urbanization across the country. This is based on the fact that hospitals in urban centers have different working conditions compared to those in rural areas. For this study, the difference might have confounding effects on nurses' intention to 
leave due to difference in social relationship. This study did not show the status of intention to leave for those working in health centers, primary hospitals, and tertiary hospitals.

\section{Conclusion And Recommendations}

This cross-sectional clustered random sampling study designed focused on the nurses' intention to leave their jobs and its associated factors of nurses working in general hospitals of Tigray Regional State. The magnitude of nurses' intention to leave their jobs is $43.90 \%$. Male nurses were more likely intended to leave their job. Nurses working in the medical ward were also intended to leave their jobs.

We suggest the health policy makers to establish a strategy of retaining nurses in their workplace and male nurses need to have economic incentives to improve their families' monthly income and keep them safe at the hospital workplace. It is recommended health managers to do a rotation of nurses within hospitals. We recommend the head nurses in medical wards to create a favorable working climate that nurses will be able to provide quality nursing care. We suggest continuing education to socialize male nurses and on mechanisms to reduce possible exhaustion and workload among nurses working in medical wards. To prevent a shortage due to actual turnovers, schools of nursing are recommended to increase intake of student nurses and incorporate training on retention of nurses and safe working environment. Other researchers are recommended to assess the intention to leave among nurses working in primary hospitals and to use longitudinal study design.

\section{Abbreviations}

and acronyms

AOR

Adjusted Odds Ratio

$\mathrm{Cl}$

Confidence Interval

COR

Crude Odds Ratio

ECSA

Ethiopian Central Statistical Agency

ETB

Ethiopian currency in Birr

$\mathrm{MCH}$

Maternal and Child Care

MOAQ

Michgan Organizational Assessment Questionnaire

OPD

Out Patient Department in hospital

SPSS 
Statistical Package for Social Science

TRHB

Tigray Regional Health Bureau

WHO

World Health Organization

\section{Declarations}

\section{Ethical considerations}

The study was approved by the Institutional Research Ethics Review Committee of the Tehran University Medical Sciences International Campus (Approval ID: IR.TUMS.VCR.REC 1397.697). The purpose of the study was explained to Tigray Regional Health Bureau, and Directors of hospitals and permission was obtained. All nurses were provided written consent, clearly stating the objectives of the study, their right to participate or their right to refuse in the study. No minors were involved in the study and the consent was obtained from each participant.

\section{Consent for publication}

Not applicable.

\section{Availability of data and materials}

The datasets used and/or analyzed during the current study is available from the corresponding author on request.

\section{Conflict of interests}

The authors declare that there is no conflict of interest in the publication of this paper.

\section{Funding}

The data collection of this research work was funded by Tehran University Medical Sciences and Adigrat University. The fund providers didn't participate in designing and data collection, analysis, writing, and submission of the article for publication.

\section{Authors' contribution}

WG wrote the proposal, facilitated the data collection, analyzed the data, and drafted the paper. RN, SP, and EN cooperate in writing the proposal and approved with some revisions. All author contributed the conception of the research question, drafted the manuscript, read and approved the final manuscript.

\section{Acknowledgment}


We would like to express our gratitude to all nurse participated in this study. Gratitude thanks to the Tehran University Medical Sciences International Campus, Facility of Nursing and Midwifery Department of Community Health and Geriatric Nursing for the provision of the ethical approval of this research. We also thank the Adigrat University for its financial support in the data collection of this research. Again we need to acknowledge the Tigray Regional Health Bureau for the provision of secondary data and writing the supportive letter of facilitation.

\section{References}

1. Global health workforce shortage to reach $\mathbf{1 2 . 9}$ million in coming decades. .

2. Mariani B. The effect of mentoring on career satisfaction of registered nurses and intent to stay in the nursing profession. Nursing research and practice 2012, 2012.

3. Mitchell G. Nurse retention 'critical' as world faces nine million shortage by 2030. In: Nursing Times. 2019.

4. Health care management and administration blog: Seven nurse retention strategies. .

5. Aiken LH, Sloane DM, Bruyneel L, Van den Heede K, Griffiths P, Busse R, Diomidous M, Kinnunen J, Kózka M, Lesaffre E. Nurse staffing and education and hospital mortality in nine European countries: a retrospective observational study. The Lancet. 2014;383(9931):1824-30.

6. LIOU SR. Nurses' intention to leave: Critically analyse the theory of reasoned action and organizational commitment model. J Nurs Adm Manag. 2009;17(1):92-9.

7. Blaauw D, Ditlopo P, Maseko F, Chirwa M, Mwisongo A, Bidwell P, Thomas S, Normand C. Comparing the job satisfaction and intention to leave of different categories of health workers in Tanzania, Malawi, and South Africa. Global health action. 2013;6(1):19287.

8. Cheng CY, Liou SR. Intention to leave of Asian nurses in US hospitals: does cultural orientation matter? Journal of clinical nursing. 2011;20(13-14):2033-42.

9. TRHB. Tigray health bureau 2014 (2007 Ethiopian fiscal year) annual profile. 2014.

10. Alsaqri S. A survey of intention to leave, job stress, burnout and job satisfaction among nurses employed in the Ha'il region's hospitals in Saudi Arabia. 2014.

11. Cammann C, Fichman M, Jenkins D, Klesh J: The Michigan organizational assessment questionnaire. Unpublished manuscript, University of Michigan, Ann Arbor 1979.

12. Armmer F, Ball C. Perceptions of horizontal violence in staff nurses and intent to leave. Work. 2015;51(1):91-7.

13. Sojane JS, Klopper HC, Coetzee SK. Leadership, job satisfaction and intention to leave among registered nurses in the North West and Free State provinces of South Africa. Curationis. 2016;39(1):1-10.

14. Sato Y, Hayashida N, Orita M, Urata H, Shinkawa T, Fukushima Y, Nakashima Y, Kudo T, Yamashita S, Takamura N. Factors associated with nurses' intention to leave their jobs after the Fukushima Daiichi Nuclear Power Plant accident. PLoS One. 2015;10(3):e0122389. 
15. Leone C, Bruyneel L, Anderson JE, Murrells T, Dussault G, de Jesus ÉH, Sermeus W, Aiken L, Rafferty AM. Work environment issues and intention-to-leave in Portuguese nurses: a cross-sectional study. Health Policy. 2015;119(12):1584-92.

16. Ramoo V, Abdullah KL, Piaw CY. The relationship between job satisfaction and intention to leave current employment among registered nurses in a teaching hospital. J Clin Nurs. 2013;22(2122):3141-52.

17. Engeda EH, Birhanu AM, Alene KA. Intent to stay in the nursing profession and associated factors among nurses working in Amhara Regional State Referral Hospitals, Ethiopia. BMC nursing. 2014;13(1):24.

18. Getie GA, Betre ET, Hareri HA. Assessment of Factors Affecting Turnover Intention Among Nurses Working at Governmental Health Care Institutions in East Gojjam, Amhara Region, Ethiopia, 2013. American Journal of Nursing Science. 2015;4(3):107-12.

19. Ayalew F, Kols A, Kim Y-M, Schuster A, Emerson MR, van Roosmalen J, Stekelenburg J, Woldemariam D, Gibson $\mathrm{H}$. Factors affecting turnover intention among nurses in Ethiopia. World health \& population 2015, 16(2).

20. Asegid A, Belachew T, Yimam E: Factors influencing job satisfaction and anticipated turnover among nurses in Sidama zone public health facilities, South Ethiopia. Nursing research and practice 2014, 2014.

21. Debela TF, Salgedo WB, Tsehay YE. Predictors of Intention-to-Leave the Current Job and Staff Turnover among Selected Health Professionals in Ethiopia. Global Journal of Management And Business Research 2017.

22. Kalifa T, Ololo S, Tafese F. Intention to leave and associated factors among health professionals in Jimma zone public health centers, southwest Ethiopia. Open Journal of Preventive Medicine. 2016;6(01):31.

23. Ferede A, Kibret GD, Million Y, Simeneh MM, Belay YA, Hailemariam D: Magnitude of Turnover Intention and Associated Factors among Health Professionals Working in Public Health Institutions of North Shoa Zone, Amhara Region, Ethiopia. BioMed research international 2018, 2018.

24. Abera E, Yitayal M, Gebreslassie M. Turnover intention and associated factors among health professionals in University of Gondar Referral Hospital, Northwest Ethiopia. Int J Econ Manag Sci. 2014;3(4):1-4.

25. Adugna Endale Woldegiorgis SOS. Fikiru Tafese Jaleta: Health professionals' intention to leave from public health facilities and its determinants in Gambella Region, Southwest Ethiopia. American Journal of Health Research. 2015;3(6):386-92.

26. Al Momani M. Factors influencing public hospital nurses' intentions to leave their current employment in Jordan. International Journal Of Community Medicine Public Health. 2017;4(6):1847-53.

27. Jeong IY, Kim JS. The relationship between intention to leave the hospital and coping methods of emergency nurses after workplace violence. Journal of clinical nursing. 2018;27(7-8):1692-701. 
28. Çaylak E, Altuntas S. Organizational silence among nurses: The impact on organizational cynicism and intention to leave work. Journal of Nursing Research. 2017;25(2):90-8.

29. Han K, Trinkoff AM, Gurses AP. Work-related factors, job satisfaction and intent to leave the current job among United States nurses. Journal of clinical nursing. 2015;24(21-22):3224-32.

30. Mazurenko O, Gupte G, Shan G. Analyzing US nurse turnover: Are nurses leaving their jobs or the profession itself. Journal of Hospital Administration. 2015;4(4):48-56.

31. Saijo Y, Yoshioka E, Kawanishi Y, Nakagi Y, Itoh T, Yoshida T. Relationships of job demand, job control, and social support on intention to leave and depressive symptoms in Japanese nurses. Industrial health 2015.

32. Perry L, Gallagher R, Duffield C, Sibbritt D, Bichel-Findlay J, Nicholls R. Does nurses' health affect their intention to remain in their current position? J Nurs Manag. 2016;24(8):1088-97.

33. Cortese CG. Predictors of critical care nurses' intention to leave the unit, the hospital, and the nursing profession. 2012.

34. Sasso L, Bagnasco A, Catania G, Zanini M, Aleo G, Watson R, Group RCIW. Push and pull factors of nurses' intention to leave. Journal of nursing management 2019.

35. Dall'Ora C, Griffiths P, Ball J, Simon M, Aiken LH. Association of $12 \mathrm{~h}$ shifts and nurses' job satisfaction, burnout and intention to leave: findings from a cross-sectional study of 12 European countries. BMJ open. 2015;5(9):e008331.

36. Rispel LC, Chirwa T, Blaauw D. Does moonlighting influence South African nurses' intention to leave their primary jobs? Global health action. 2014;7(1):25754.

37. Jiang H, Ma L, Gao C, Li T, Huang L, Huang W. Satisfaction, burnout and intention to stay of emergency nurses in Shanghai. Emerg Med J 2017:emermed-2016-205886.

38. Zhang L-f, You L-m, Liu K, Zheng J, Fang J-b, Lu M-m, Lv A-I, Ma W-g, Wang J, Wang S-h. The association of Chinese hospital work environment with nurse burnout, job satisfaction, and intention to leave. Nurs Outlook. 2014;62(2):128-37.

39. Zhang Y, Wu J, Fang Z, Zhang Y, Wong FKY. Newly graduated nurses' intention to leave in their first year of practice in Shanghai: A longitudinal study. Nurs Outlook. 2017;65(2):202-11.

40. Tesfaye T, Abera A, Hailu F, Nemera G, Belina S. Assessment of factors affecting performance of nurses working at Jimma University Specialized Hospital in Jimma Town, Oromia Region, SouthWest Ethiopia. J Nurs Care. 2015;4(6):312.

41. Fantahun A, Demessie A, Gebrekirstos K, Zemene A, Yetayeh G: A cross sectional study on factors influencing professionalism in nursing among nurses in Mekelle Public Hospitals, North Ethiopia, 2012. BMC nursing 2014, 13(1):10.

42. Semachew A, Belachew T, Tesfaye T, Adinew YM. Predictors of job satisfaction among nurses working in Ethiopian public hospitals, 2014: institution-based cross-sectional study. Human resources for health. 2017;15(1):31. 
43. Negussie N. Relationship between rewards and nurses' work motivation in Addis Ababa hospitals. Ethiopian journal of health sciences 2012, 22(2).

44. Alsaraireh F, Quinn Griffin MT, Ziehm SR, Fitzpatrick JJ. Job satisfaction and turnover intention among $\mathrm{J}$ ordanian nurses in psychiatric units. Int J Ment Health Nurs. 2014;23(5):460-7.

45. Toren O, Zelker R, Lipschuetz M, Riba S, Reicher S, Nirel N. Turnover of Registered Nurses in Israeli Hospitals: A Secondary Analysis From A National Survey. International Journal of Translational Research. 2017;1(1):1.

46. Goh YS, Lopez V. Job satisfaction, work environment and intention to leave among migrant nurses working in a publicly funded tertiary hospital. J Nurs Adm Manag. 2016;24(7):893-901.

47. Baum A, Kagan I. Job satisfaction and intent to leave among psychiatric nurses: closed versus open wards. Arch Psychiatr Nurs. 2015;29(4):213-6.

48. Dyo M, Kalowes P, Devries J. Moral distress and intention to leave: a comparison of adult and paediatric nurses by hospital setting. Intensive Critical Care Nursing. 2016;36:42-8. 